Bond University

Research Repository

\title{
Does a Novice Technician Produce Results Similar to That of an Experienced DXA Technician When Assessing Body Composition and Bone Mineral Density?
}

Persson, Carl; Shiel, Flinn; Climstein, Mike; Furness, James

Published in:

International Journal of Sport Nutrition and Exercise Metabolism

DOI:

10.1123/ijsnem.2018-0299

Licence:

Free to read

Link to output in Bond University research repository.

Recommended citation(APA):

Persson, C., Shiel, F., Climstein, M., \& Furness, J. (2019). Does a Novice Technician Produce Results Similar to That of an Experienced DXA Technician When Assessing Body Composition and Bone Mineral Density? International Journal of Sport Nutrition and Exercise Metabolism, 29(4), 1-19.

https://doi.org/10.1123/ijsnem.2018-0299

\section{General rights}

Copyright and moral rights for the publications made accessible in the public portal are retained by the authors and/or other copyright owners and it is a condition of accessing publications that users recognise and abide by the legal requirements associated with these rights.

For more information, or if you believe that this document breaches copyright, please contact the Bond University research repository coordinator 
5 Does a novice technician produce results similar to that of an experienced DXA

technician when assessing body composition and bone mineral density?

$9 \quad$ Carl Persson $^{1}$, Flinn Shiel ${ }^{1}$, Mike Climstein ${ }^{2,3,4}$, James Furness ${ }^{1,2}$.

101 Faculty of Health Sciences and Medicine, Bond University, Gold Coast, QLD 4226,

$11 \quad$ Australia

122 Water Based Research Unit, Bond Institute of Health \& Sport, Bond University, Gold

13 Coast, QLD 4226

143 School of Health and Human Sciences, Southern Cross University, Lismore, NSW, 15 Australia,

164 Exercise, Health \& Performance Faculty Research Group, Faculty of Health Sciences, The

17 University of Sydney, Sydney, NSW, Australia

18

19 Address for correspondence: Dr James Furness, PhD, Faculty of Health Sciences and

20 Medicine, Bond University, Robina, QLD, Australia. Email: jfurness@bond.edu.au

22 Running title - Are novice DXA technicians results similar to experienced? 


\section{ABSTRACT}

24 Dual energy X-ray absorptiometry is a commonly used clinical assessment tool for body composition and bone mineral density, which is gaining popularity in athletic cohorts. Results from body composition scans are useful for athletic populations to track training and nutritional interventions, whilst bone mineral density scans are valuable for athletes at risk of developing stress fractures due to low bone mineral density. However, no research has ascertained if a novice technician (accredited but not experienced) could produce similar results to an experienced technician. Two groups of recreational athletes were scanned, one by an experienced technician, one by a novice technician. All participants were scanned twice with repositioning between scans. The experienced technician's reliability (ICC $0.989-0.998$, percentage change in mean $-0.01-0.10$ ), precision (typical error as CV\% 0.01 to 0.47 . standard error of measurement percentage $0.61 \%-1.39 \%$ ) and sensitivity to change (smallest real difference percentage $1.70 \%-3.85 \%$ ) were similar, however superior, to those of the novice technician. The novice technician results were: reliability (ICC $0.985-0.997$, percentage change in mean $-0.03-0.23$ ), precision (typical error as CV\% $0.03-0.75 \%$, standard error of measurement percentage $1.06 \%-2.12 \%$ ) and sensitivity to change (smallest real difference percentage $2.73 \%$ - 5.86\%). Extensive experience whilst valuable is not a necessary requirement to produce quality results when undertaking whole body dual energy X-ray absorptiometry scanning.

\section{KEYWORDS}

44 Reliability; Precision; sensitivity to change; 


\section{INTRODUCTION}

49 Low bone mineral density (BMD) and associated conditions such as osteoporosis and osteopenia are health problems that annually costs over 830 million dollars in Australia and osteoporosis is a significant cause of morbidity and mortality (Johnell et al., 2006; Watts et al., 2013). The need to accurately and effectively measure whole body and segmental BMD led to the development of the DXA scanner, which is now considered the gold standard for BMD and body composition (Blake et al., 2007; Lewiecki, 2005). Low BMD (osteoporosis and osteopenia) is a concern for the general population as well as athletic population, as low BMD increases the risk of stress or fragility fractures while an athlete is actively training, competing and later in life (Kelsey et al., 2007; Scofield et al., 2012). Reduced cortical mass can predispose athletes to lower limb stress fractures, with the incidence rate being as high at $20 \%$ annually in track and field athletes (Bennell et al., 1996). Additionally, it is recognised that endurance athletes (female runners and swimmers, male cyclists) and athletes who did not partake in loaded and/or impact activities and sports as teens are at a higher risk of having low BMD and subsequently developing bony stress related conditions (Fredericson et al., 2005; Tenforde et al., 2015). This is due to factors including female athlete triad and excessive time spent in sport with low cortical stress leading to weakened bone strength (Chen et al., 2013; Fredericson et al., 2005; Tenforde et al., 2015). Therefore, screening these athletes via DXA can act as an injury prevention tool for early intervention. If stress fractures are not correctly treated and healed, they can result in a reduction in performance, an increase in pain, a loss of training time and medical expenses; subsequent development of a complete fracture, nonunion, chronic pain, increased recovery time and possibly disability (Chen et al., 2013; Schnackenburg et al., 2011). 
72 Additionally, DXA's ability to assess whole body and segmental body composition (BC) including lean mass (LM), fat mass (FM) and bone mineral content (BMC) has become an important tool in the measurement of $\mathrm{BC}$ and is used in clinical, sporting and research settings and is considered the reference standard (Buckinx et al., 2018). In the sporting setting, it is known that LM and FM impact physical performance and the risk of injury and illness (Duthie, 2006; Georgeson et al., 2011; Hagmar et al., 2013; Stewart, 2001). Therefore, it is common practice among the professional sporting population to have regular $\mathrm{BC}$ assessments to track the effectiveness of training or nutritional interventions as any small change to BC can impact performance (Duthie, 2006).

The International Society for Clinical Densitometry (ISCD) recommends precise measures during preparation and positioning of the participant of a DXA BC scan (ISCD, 2015). For whole body analysis of BC it has been shown that sources of biological error in DXA results include hydration, stomach content and food consumption, time of day of scanning and prescan physical activity (Hangartner et al., 2013; Nana et al., 2012, 2013). Furthermore sources of technical error include artifacts such as clothing, number of technicians used to complete scans and position of participant (Hangartner et al., 2013; Kiebzak et al., 2000; Kerr et al., 2016; Nana et al., 2012). Given the importance of positioning, it is crucial the DXA technician adheres to established best practice to ensure the most accurate and reliable results.

It has been reported that up to $64 \%$ of scans were deemed inadequate as they did not provide sufficient accuracy when automatic analysis was applied and that manual analysis should be undertaken, therefore the skill of the DXA scanning technician is vitally important (Baniak et al., 2014). However, to date no research has focused on whether the experience of the DXA scanner influences BC and BMD results. Kim et al. (2014) suggest a DXA technologist is 
97 sufficiently experienced after performing repeated training in which the technologist

114 Therefore, the aim of this study is to ascertain if a novice technician can produce whole body undertakes adjusting patient positioning, device manipulation and result analysis on 100 patients.

The increasing popularity to use DXA to assess and track change in BC and BMD over time has created a larger need for qualified DXA technicians. As such, Australian (Kerr et al., 2016) and USA universities (Standorth et al., 2016; Trexler et al., 2018) possess DXA scanners to conduct research assessing BC and BMD in athletic/non-athletic and clinical (Newton et al., 2009) populations. However, the demand for scanning may lead to novice technicians being utilised and even though these technicians are accredited, they may not have the extended training and experience using the device to attain accurate and reliable results.

As such, the rationale for this study was that the DXA data being collected by a novice technician was showing high quality results. The question was then asked, how close were the results of a novice technician to those already obtained by an experienced technician utilising the same DXA scanner?

BC and BMD DXA scanning results similar to that of an experienced technician when scanning recreational athletes.

\section{METHODS}

\section{Study Design}

In order to assess the novice and experienced technicians’ reliability, precision and sensitivity to change individuals were assigned to a group (experienced or novice). Individuals total body 
123 BC and BMD were scanned twice on the same day, minutes apart with repositioning between

124 each scan. Scanning took place in accordance with positioning protocols developed by Alisa

125 Nana as illustrated in Figure 1. (Nana et al., 2012). The study had ethical approval Bond 126 University Human Research Ethics Committee (RO15221, RO1655).

\section{Participants}

129 A total of 38 participants were included in this two-part pilot study. Eight participants formed

130 the experienced technicians’ group, which was a convenience sample. These eight

131 participants were scanned twice by the same experienced technician to establish their own

132 reliability. The second group (novice technician’s group), which consisted of 30 participants,

133 was scanned twice by the same novice technician to determine his reliability. Ethical

134 approval was only granted for individual's to be scanned twice due to concerns over radiation 135 exposure.

136

137 All participants recruited were aged over eighteen, recreational athletes and were from the local 138 geographical area. To be eligible for the study, participants must have been willing to meet scanning stipulations (fasted, bladder voided, removal of metal, abstained from exercise on day of scan and undertake anthropometric assessment). Participants were excluded from the study;

141 if the participant competed in collegiate or professional sport, suspected they were pregnant

142 and or were non-healthy: inclusive of osteoporosis, current fractures, hemiarthroplasty and 143 total joint replacements, rheumatoid or osteoarthritis, current cardiac or pulmonary conditions, 144 diabetes or if they were unable to maintain the required position for the duration of the scans.

145 To reduce the likelihood of artifacts, male participants wore underwear during scanning while 146 female participants wore underwear, sports bra or two-piece bathers. Participants initially were 147 informed of all testing procedures and questions were answered at that time prior to signing 
148 the voluntary consent form. No participants who were invited to participate in the study

149 declined to participate. Participants were assessed for height (to the nearest $1.0 \mathrm{~cm}$ ) using a 150 stadiometer (Harpenden, Holtain Limited, Crymych, UK) and mass (to the nearest 100 grams)

151 using calibrated scales (WM202, Wedderburn, Bilinga, Australia) prior to scanning.

152

\section{Technicians}

154 Both technicians were accredited and trained through the Australia and New Zealand Bone Mineral Society (ANZBMS). The ANZBMS accreditation is the only certification course available which satisfies the requirements of radiation safety legislation in Australia, leading to licensure. Both technicians undertook the same accreditation process. The accreditation course consists of theoretical knowledge and practical skills involved with DXA usage, including bone pathology, device usage, manipulation and the analysis of results. Prior to this study the novice technician's previous experience was approximately 25 DXA scans. The experienced technician was deemed so, as they had completion of more than 100 scans as well as having a five-year history as a DXA technician (Kim et al., 2014).

163

164 Equipment

165 All scans were performed using a narrow angle fan beam Lunar Prodigy DXA scanner (GE 166 Healthcare, Madison, WI). Scans were analysed automatically by the GE enCORE 2016 167 software (GE Healthcare). Scans were then analysed by the DXA technician and region of 168 interest lines adjusted accordingly, if needed, relative to the ANZBMS guidelines. The DXA scanner was calibrated daily using a whole body phantom as per manufacturer's guidelines prior to any scans.

\section{Statistical Analysis}


173 All data was analysed using IBM statistical package for the social sciences (SPSS, version 24)

174 or via a customised reliability spreadsheet from sportsci.org. To analyse test re-test reliability 175 the recommended Intraclass Correlation Coefficient $(3,1)$ with 95\% confidence intervals was 176 performed using SPSS (Ionan et al., 2014; Trevethan, 2016). The ICC results were interpreted 177 as indicators of reliability as follows: ICC of $0.00-0.29$, very low reliability; $0.30-0.49$, low 178 reliability; 0.50-0.69, moderate reliability; 0.70-0.89, high reliability; and 0.90-1.00, very 179 high reliability (Munro et al., 2005). Additionally, SPSS was used to calculate the standard 180 error of measurement percentage (SEM\%) (Equation 1) and smallest real difference percentage 181 (SRD\%) (Equation 2) (Lexell et al., 2005). Acceptable precision of results has been previously 182 set by ISCD at 2\% for LM and 2\% for FM respectively (ISCD, 2015).

$\mathrm{SEM}=((\sqrt{ }$ mean square error from ANOVA $) /$ mean $) \times 100$,

$\operatorname{SRD} \%=((1.96 \times \operatorname{SEM} \times \sqrt{2}) /$ mean $) \times 100$,

183 A customised spreadsheet from Sportscience website (www.sportsci.org) was utilised to 184 calculate and analyse percentage change in mean and the accompanying typical error 185 (coefficient of variation (CV\%) percentage) as recommended (Hopkins, 2000; Hopkins et al., 2009).

187

\section{$188 \quad$ RESULTS}

189 Anthropometrical data (mean + SD) of the participants are presented in Table 1. Independent

190 T-tests for age, height, weight, BMI, whole body FM percentage, whole body LM percentage,

191 whole body BMC percentage and whole body BMD revealed no significant differences

192 between the novice and experienced groups $(\mathrm{p}=0.96,0.45,0.21,0.35,0.13,0.06,0.01,0.49$ 193 respectively) except for BMC. 
195 All the collated results from the experience and novice technicians' reliability, precision and sensitivity to change are presented in Table 2. Both technicians ICC reliability values were

197 within the high to very high range (Munro et al., 2005)

\section{Experienced technician}

199 Scan 1 produced the following absolute values: FM 23.01\%, LM 73.69\%, BMC \% 3.30\%,

200 BMD 1.275 g.cm ${ }^{-2}$. Scan 2 produced the following 23.13\%, 73.65\%, 3.31\%, 1.274 g/cm², 201 difference of $0.12 \%, 0.04 \%, 0.01 \%$ and $0.001 \mathrm{~g} / \mathrm{cm}^{2}$ which was evident in the high reliability 202 scores.

\section{Novice technician}

Scan 1 produced the following absolute values: FM 25.91\%, LM 70.21\%, BMC \% 3.87, BMD of $0.05 \%, 0.18 \%, 0.02 \%$ and $0.004 \mathrm{~g} / \mathrm{cm}^{2}$ which was evident in the high reliability scores.

\section{DISCUSSION}

210 The purpose of this study was to ascertain if a novice but accredited DXA technician could

211 produce results similar to that of an experienced DXA technician. DXA reliability has been 212 studied extensively in both the facets of whole body and segmental BC (Bilsborough et al., 213 2014; Kerr et al., 2016; Nana et al., 2012, 2013) and region specific BMD (Fuller et al., 2016; 214 Lohman et al., 2009). To our knowledge, there is no study to date that has assessed the 215 reliability, precision or sensitivity to change of BC or BMD scanning when completed by a 216 novice technician. Our results indicated that when an accredited, but novice technician uses the

217 Lunar DXA scanner to assess BC and BMD they produce results that are similar, yet slightly 218 inferior to that of an experienced technician. 
220 The novice and the experienced technician produced very similar fat percentage results. Both technicians achieved very high test-retest reliability (ICC 0.995 and 0.996, and 0.996, 0.10 and 0.23 percentage change in mean) and the results are similar to previously published data (ICC 0.98 to 0.99, percentage change in mean 0.0 to 0.4) (Bilsborough et al., 2014; Kerr et al., 2016; Nana et al., 2012, 2013). However, the percentage fat parameter produced the worst precision (SEM\%) and poorest sensitivity to change (SRD\%) statistics compared with the parameters of bone and LM. This is due to the fat parameter producing the largest variance (error rate) of the parameters. This finding of fat tissue producing poorer reliability results is consistent across several BC studies (Bilsborough et al., 2014; Kerr et al., 2016; Nana et al., 2012, 2013), which is then exacerbated when calculating SEM and SRD. Additionally, the novice technicians group had a larger fluctuation in stature of participants with some (n-7) only just fitting within the scanning field, which would have increased the statistical variance. This increase in statistical variance contributed to the experienced technician having better precision (CV\% 0.33 vs 0.36 , SEM\% $1.39 \%$ vs 2.12 ) and sensitivity to change (SRD\% 3.85\% vs $5.86 \%$ ). However, the precision results (CV\%) $(0.36 \%$ and $0.33 \%$ respectively) of the novice and experienced technicians falls well below the range of previously published CV\% data of 1.3 to 5.9\% (Bilsborough et al., 2014; Kerr et al., 2016; Nana et al., 2012, 2013). It should be noted that the sensitivity to change (SEM\%) of the experienced technician $(1.39 \%)$ is well below the ISCD recommend precision (2\%) (ISCD, 2015), indicating superior precision, however the SEM\% (2.12\%) of the novice is just above the recommend precision illustrating that the novice's precision was slightly worse than recommended and may be due to inexperience in positioning and assessing scans, or the larger fluctuation of stature creating higher statistical variance. 
244 The novice technician had slightly better reliability results when assessing the lean mass

245 parameter (ICC 0.996 vs 0.989 , percentage change in mean -0.03 vs -0.10 ) however the

246 experienced technician demonstrated better precision (CV\% 0.47 vs CV\% 0.75, SEM\% 0.61

247 vs $1.46 \%$ ) and sensitivity to change (SRD\% 1.70 vs 4.05). The reliability of the novice and

248 experienced technician is slightly lower than previously published data when using the ICC

249 statistic (0.996 and 0.989 vs 1.00$)$, however all results are deemed as very high reliability

250 (Munro et al., 2005). When using the percentage change in mean statistic the results are very

251 similar ( -0.03 and -0.10 vs range of 0.0 to 0.3 .) This fluctuation in reliability results may be

252 due to the type of athlete scanned in the previous studies (professional athletes versus

253 recreational) and the variances in the statistical analysis. When assessing precision the novice

254 and experienced technicians results (CV\% 0.75 and 0.47 ) fall into the lower end of the

255 published data range (0.3 to $1.5 \%)$ and the SEM\% (0.61 to $1.46 \%)$ is well within the ISCD

256 recommendations (2\%) (ISCD, 2015), indicating high precision by the technicians in this

257 study.

258

259 When assessing the reliability of BMC\% the novice technician produced a slightly higher ICC

260 (0.997 vs 0.994), both of which are deemed as very high (Munro et al., 2005). When comparing

261 the experienced and novice technicians the reliability, when using the ICC statistic is very

262 similar to previously published data (Bilsborough et al., 2014), and at the lower end of the

263 published percentage change in mean (0.02 vs $0.00-1.9 \%)$. The precision of both technicians

264 is very good with the experienced technician producing slightly better SEM\% (0.88\% vs 1.1\%),

265 which may be due to the smaller sample size of the experienced technician. The precision when

266 expressed as CV\% is very low (0.03) in comparison to the large range displayed in previous

267 studies (0.06 - 5.2\%) (Bilsborough et al., 2014; Kerr et al., 2016; Nana et al., 2012, 2013),

268 indicating that both the experienced and novice technicians in this study produced very precise 
results when assessing BMC\%. The sensitivity to change of the experienced technician is also lower than the novice technician (2.44\% vs 3.10\%) indicating better results.

The reliability of the experienced technician (ICC 0.998) is very high and is clearly more superior to the novice technician's high reliability (0.985) (Munro et al., 2005). Not surprisingly the precision of the experienced technician is also more superior to that of the novice (CV\% 0.01 vs 0.14 , SEM\% 0.70 vs $1.06 \%$ ). Previously, BMD analysis has been used on site-specific basis i.e. lumbar spine, hip to assess for changes after the occurrence of symptoms, however for this study it was assessed for the entire body as it was being utilised as a screening tool for those at risk of developing bony stress related injuries. As such there has been no reliability data published, however the results of this study (experienced $1.27+0.20$ g.cm \pm 0.11 , inexperienced $1.31+0.11$ g. $\left.\mathrm{cm}^{2}\right)$ in terms of grams per centimeter squared are similar to those of previously published data $\left(1.04 \pm 0.07\right.$ to $\left.1.31 \pm 0.08 \mathrm{~g} / \mathrm{cm}^{2}\right)$ of athletes who are involved in sports that are deemed high risk for stress reactions due to low BMD (Andreoli et al., 2001; Ferry et al., 2011).

One identified limitation was the use of whole-body BMD measurement as opposed to sitespecific BMD measurements because the technology embedded in the BC scan allows for whole body BMD analysis, subsequently reducing the levels of exposure to radiation. For this reason, professional athletes who routinely have BC scan should include a whole-body BMD assessment from the BC scans. The authors recommend that if the whole-body BMD scans results were to show a cause for concern, a segmental site specific BMD can then be undertaken.

Furthermore, this study only assessed one experienced technician and one novice technician, using two different sample groups of different sizes, as significant multiple scanning and 
294

295

296

297

298

299

300

301

302

303

304

305

306

307

308

309

310

311

312

313

314

315

316

317

exposure to radiation was an ethical consideration. Ideally, future research should include multiple technicians scanning large participant cohorts in a cross-sectional design to further validate the findings of this study and minimise the impact of a single technician. To be able to further generalise the findings the sample population should include both recreational and professional athletes.

In summary, the high to very high reliability results of DXA scanning for both technicians compared with previously published data illustrates that extensive experience whilst valuable is not necessarily a requirement to produce quality results. In a climate where DXA use is becoming a more common place, the results of this study will provide the novice technician with more confidence when completing DXA scanning.

\section{ACKNOWLEDGMENTS}

This study was granted ethics approval from Bond University Human Research Ethics Committee (RO15221, RO1655). The authors received no funding for this work and have no conflicts of interest. The authors would like to thank the participants for partaking in the study, the graduating Physiotherapy cohort of 2017, and Vini Simas for his time and effort in completing the scans. This study was designed by MC and FS; data were collected by FS and CP; data interpretation and manuscript preparation were undertaken by CP, FS, M.C and J.F. All authors approved the final version of the paper.

\section{REFERENCES}

Andreoli, A., Monteleone, M., Van Loan, M., Promenzio, L., Tarantino, U., \& De Lorenzo, A. (2001). Effects of different sports on bone density and muscle mass in highly trained athletes. Medicine \& Science in Sports \& Exercise, 33(4), 507 - 511. 
318 Baniak, N., Grzybowski, S., \& Olszynski, W. P. (2014). Dual-Energy X-ray Absorptiometry Scan Autoanalysis vs Manual Analysis. Journal of Clinical Densitometry, 17(1), 97103.

321

Bennell, K. L., Malcolm, S. A., Thomas, S. A., Reid, S. J., Brukner, P. D., Ebeling, P. R., \& Wark, J. D. (1996). Risk factors for stress fractures in track and field athletes. A twelve-month prospective study. The American journal of sports medicine, 24(6), 810-818.

Bilsborough, J. C., Greenway, K., Opar, D., Livingstone, S., Cordy, J., \& Coutts, A. J. (2014). The accuracy and precision of DXA for assessing body composition in team sport athletes. Journal of sports sciences, 32(19), 1821-1828. doi:10.1080/02640414.2014.926380

Blake, G. M., \& Fogelman, I. (2007). The role of DXA bone density scans in the diagnosis and treatment of osteoporosis. Postgraduate Medical Journal, 83(982), 509-517. doi:10.1136/pgmj.2007.057505

Buckinx, F., Landi, F., Cesari, M., Fielding, R. A., Visser, M., Engelke, K., . . . Kanis, J. A. (2018). Pitfalls in the measurement of muscle mass: a need for a reference standard. $J$ Cachexia Sarcopenia Muscle, 9(2), 269-278. doi:10.1002/jcsm.12268

Chen, Y.-T., Tenforde, A. S., \& Fredericson, M. (2013). Update on stress fractures in female athletes: epidemiology, treatment, and prevention. Current Reviews in Musculoskeletal Medicine, 6(2), 173-181. doi:10.1007/s12178-013-9167-x

Duthie, G. M. (2006). A framework for the physical development of elite rugby union players. Int J Sports Physiol Perform, 1(1), 2-13.

Ferry, B., Duclos, M., Burt, L., Therre, P., Le Gall, F., Jaffré, C., \& Courteix, D. (2011). Bone geometry and strength adaptations to physical constraints inherent in different 
sports: comparison between elite female soccer players and swimmers. Journal of Bone and Mineral Metabolism, 29(3), 342-351.

Fredericson, M., Ngo, J., \& Cobb, K. (2005). Effects of ball sports on future risk of stress fracture in runners. Clin J Sport Med, 15(3), 136-141.

Fuller, J. T., Archer, J., Buckley, J. D., Tsiros, M. D., \& Thewlis, D. (2016). The reliability of dual-energy X-ray absorptiometry measurements of bone mineral density in the metatarsals. Skeletal Radiology, 45(1), 135-140. doi:10.1007/s00256-015-2227-0

Georgeson, E. C., Weeks, B. K., McLellan, C. P., \& Beck, B. R. (2011). Body Composition Change Over a Professional Rugby League Season and Relationship to Rates and Types of Injury. Medicine \& Science in Sports \& Exercise, 43(5 (Suppl 1)), 108.

Hagmar, M., Berglund, B., Brismar, K., \& Hirschberg, A. L. (2013). Body composition and endocrine profile of male Olympic athletes striving for leanness. Clin J Sport Med, 23(3), 197-201. doi:10.1097/JSM.0b013e31827a8809

Hangartner, T. N., Warner, S., Braillon, P., Jankowski, L., \& Shepherd, J. (2013). The Official Positions of the International Society for Clinical Densitometry: acquisition of dual-energy X-ray absorptiometry body composition and considerations regarding analysis and repeatability of measures. Journal of Clinical Densitometry, 16(4), 520536. doi:10.1016/j.jocd.2013.08.007

Hopkins, W. G. (2000). Measures of Reliability in Sports Medicine and Science. Sports Medicine, 30(1), 1-15. doi:10.2165/00007256-200030010-00001

Hopkins, W. G., Marshall, S. W., Batterham, A. M., \& Hanin, J. (2009). Progressive statistics for studies in sports medicine and exercise science. Medicine \& Science in Sports \& Exercise, 41(1), 3-13. doi:10.1249/MSS.0b013e31818cb278

International Society Clinical Densitometry (ISCD). (2015). ISCD 2015 Adult Official Positions. Middletown, CT, USA: ISCD. 
Ionan, A. C., Polley, M.-Y. C., McShane, L. M., \& Dobbin, K. K. (2014). Comparison of confidence interval methods for an intra-class correlation coefficient (ICC). BMC Medical Research Methodology, 14, 121. doi:10.1186/1471-2288-14-121

Johnell, O., \& Kanis, J. A. (2006). An estimate of the worldwide prevalence and disability associated with osteoporotic fractures. Osteoporos Int, 17(12), 1726-1733. doi:10.1007/s00198-006-0172-4

Kelsey, J. L., Bachrach, L. K., Procter-Gray, E., Nieves, J., Greendale, G. A., Sowers, M., .. . Cobb, K. L. (2007). Risk factors for stress fracture among young female crosscountry runners. Medicine \& Science in Sports \& Exercise, 39(9), 1457-1463. doi:10.1249/mss.0b013e318074e54b

Kerr, A., Slater, G. J., Byrne, N., \& Nana, A. (2016). Reliability of 2 Different Positioning Protocols for Dual-Energy X-ray Absorptiometry Measurement of Body Composition in Healthy Adults. Journal of Clinical Densitometry, 19(3), 282-289. doi:10.1016/j.jocd.2015.08.002

Kiebzak, G. M., Leamy, L. J., Pierson, L. M., Nord, R. H., \& Zhang, Z. Y. (2000). Measurement precision of body composition variables using the lunar DPX-L densitometer. Journal of Clinical Densitometry, 3(1), 35-41.

Kim, H. S., \& Yang, S. O. (2014). Quality control of DXA system and precision test of radiotechnologists. J Bone Metab, 21, 2-7.

Lewiecki, E. M. (2005). Clinical applications of bone density testing for osteoporosis. Minerva medica, 96(5), 317-330.

Lexell, J. E., \& Downham, D. Y. (2005). How to assess the reliability of measurements in rehabilitation. Am J Phys Med Rehabil, 84(9), 719-723.

Lohman, M., Tallroth, K., Kettunen, J. A., \& Marttinen, M. T. (2009). Reproducibility of dual-energy x-ray absorptiometry total and regional body composition measurements 
392

393

394

395

396

397

398

399

400

401

402

403

404

405

406

407

408

409

410

411

412

413

414

415

416

using different scanning positions and definitions of regions. Metabolism: clinical and experimental, 58(11), 1663-1668. doi:10.1016/j.metabol.2009.05.023

Munro, B., \& Visintainer, M. (2005). Statistical methods for health care research (5th ed. Vol. 1): Lippincott, Philadelphia.

Nana, A., Slater, G. J., Hopkins, W. G., \& Burke, L. M. (2012). Effects of daily activities on dual-energy X-ray absorptiometry measurements of body composition in active people. Medicine \& Science in Sports \& Exercise, 44(1), 180-189. doi:10.1249/MSS.0b013e318228b60e

Nana, A., Slater, G. J., Hopkins, W. G., \& Burke, L. M. (2013). Effects of exercise sessions on DXA measurements of body composition in active people. Medicine \& Science in Sports \& Exercise, 45(1), 178-185. doi:10.1249/MSS.0b013e31826c9cfd

Newton, R., Taaffe, D., Spry, N., Gardiner, R., Levin, G., Wall, B., . . Galvao, D. (2009). A phase III clinical trial of exercise modalities on treatment side-effects in men receiving therapy for prostate cancer. BMC Cancer, 9, 210.

Schnackenburg, K. E., Macdonald, H. M., Ferber, R., Wiley, J. P., \& Boyd, S. K. (2011). Bone quality and muscle strength in female athletes with lower limb stress fractures. Medicine \& Science in Sports \& Exercise, 43(11), 2110-2119. doi:10.1249/MSS.0b013e31821f8634

Scofield, K. L., \& Hecht, S. (2012). Bone health in endurance athletes: runners, cyclists, and swimmers. Curr Sports Med Rep, 11(6), 328-334. doi:10.1249/JSR.0b013e3182779193

Standorth, D., Stults-Kolemainen, M., \& Stanforth, P. (2016). Bone Mineral Content and Density Among Female NCAA Division I Athletes Across the Competitive Season and Over a Multi-Year Time Frame. . Journal of Strength \& Conditioning Research, 30(10), 2828-2838. 
417

418

419

420

421

422

423

424

425

426

427

428

429

430

431

432

433

Stewart, A. D. (2001). Assessing body composition in athletes. Nutrition, 17(7-8), 694-695.

Tenforde, A. S., Sainani, K. L., Carter Sayres, L., Milgrom, C., \& Fredericson, M. (2015). Participation in ball sports may represent a prehabilitation strategy to prevent future stress fractures and promote bone health in young athletes. Pm r, 7(2), 222-225. doi:10.1016/j.pmrj.2014.09.017

Trevethan, R. (2016). Intraclass correlation coefficients: clearing the air, extending some cautions, and making some requests. Health Services and Outcomes Research Methodology, 1-17. doi:10.1007/s10742-016-0156-6

Trexler, E., Smith-Ryan, A., Mann, J., Ivey, P., Hirsch, K., \& Mock, M. (2018). Longitudinal body composition changes in NCAA division I college football players. . Journal of Strength \& Conditioning Research, 31(1), 1-8.

Watts, J.J.; Abimanyi-Ochom, J.; Sander, K.M. (2013). Osteoporosis costing all Australians. A new burden of disease analysis - 2012 to 2022: Osteoporosis Australia.

\section{TABLES}

Table 1. Demographical Data

\begin{tabular}{|c|c|c|c|c|c|c|c|c|}
\hline & $\begin{array}{l}\text { Age } \\
\text { (years) }\end{array}$ & $\begin{array}{l}\text { Height } \\
(\mathrm{cm})\end{array}$ & $\begin{array}{l}\text { Mass } \\
\text { (kgs) }\end{array}$ & $\begin{array}{l}\text { BMI } \\
\text { (range) }\end{array}$ & FM \% & LM \% & BMC\% & $\begin{array}{l}\text { BMD } \\
\left(\mathrm{g} / \mathrm{cm}^{2}\right)\end{array}$ \\
\hline Expe & $\begin{array}{l}29.2 \pm \\
11.5\end{array}$ & $\begin{array}{l}175.8 \\
+2.6 \\
\end{array}$ & $\begin{array}{l}78.75 \\
+6.9 \\
\end{array}$ & $\begin{array}{l}23.0 \text { to } \\
29.2\end{array}$ & $\begin{array}{l}23.07 \\
+4.49\end{array}$ & $\begin{array}{l}73.62 \\
+4.30 \\
\end{array}$ & $\begin{array}{l}3.31 \pm \\
0.51\end{array}$ & $\begin{array}{l}1.27+ \\
0.19\end{array}$ \\
\hline No & $\begin{array}{l}29.6 \pm \\
10.0\end{array}$ & $\begin{array}{l}171.7 \\
+10.7\end{array}$ & $\begin{array}{l}70.6 \pm \\
12.4\end{array}$ & $\begin{array}{l}19.4 \text { to } \\
31.7\end{array}$ & $\begin{array}{l}26.03 \\
+7.29\end{array}$ & $\begin{array}{l}70.07 \\
+7.03\end{array}$ & $\begin{array}{l}3.89 \pm \\
0.45\end{array}$ & $\begin{array}{l}1.31+ \\
0.11\end{array}$ \\
\hline
\end{tabular}

cm - centrimetres, kgs - kilograms, FM \% - Fat mass perecentage, LM \% - Lean mass percentage, BMC\% - bone 


\begin{tabular}{|c|c|c|c|c|c|c|c|}
\hline & & ICC & CI & $\% \Delta$ in Mean & CV\% & SEM\% & SRD\% \\
\hline \multirow{4}{*}{ 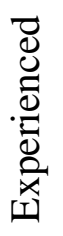 } & Fat \% & 0.995 & $0.976-0.999$ & 0.10 & 0.33 & $1.39 \%$ & $3.85 \%$ \\
\hline & Lean \% & 0.989 & $0.949-0.998$ & -0.10 & 0.47 & $0.61 \%$ & $1.70 \%$ \\
\hline & BMC (g) & 0.994 & $0.973-0.999$ & 0.02 & 0.03 & $0.88 \%$ & $2.44 \%$ \\
\hline & $\mathrm{BMD} \mathrm{g} / \mathrm{cm}^{2}$ & 0.998 & $0.991-1.000$ & -0.01 & 0.01 & $0.70 \%$ & $1.90 \%$ \\
\hline \multirow{4}{*}{ 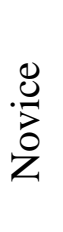 } & Fat $\%$ & 0.996 & $0.990-0.998$ & 0.23 & 0.36 & $2.12 \%$ & $5.86 \%$ \\
\hline & Lean \% & 0.996 & $0.991-0.998$ & -0.03 & 0.75 & $1.46 \%$ & $4.05 \%$ \\
\hline & BMC (g) & 0.997 & $0.993-0.999$ & 0.02 & 0.03 & $1.10 \%$ & $3.10 \%$ \\
\hline & $\mathrm{BMD} \mathrm{g} / \mathrm{cm}^{2}$ & 0.985 & $0.970-0.993$ & -0.04 & 0.14 & $1.06 \%$ & $2.73 \%$ \\
\hline
\end{tabular}

439

$\mathrm{g} / \mathrm{cm}^{2}$ - grams per centimetre squared, \% $\Delta$ in Mean - percentage change in mean, CV-confidence variance (typical error),

440

ICC - intraclass correlation coefficient, CI - confidence interval, SEM\% - percentage standard error of measurement, SRD\%

441

- percentage smallest real difference

442

443

444

445

\section{FIGURES}

446

447

448

449

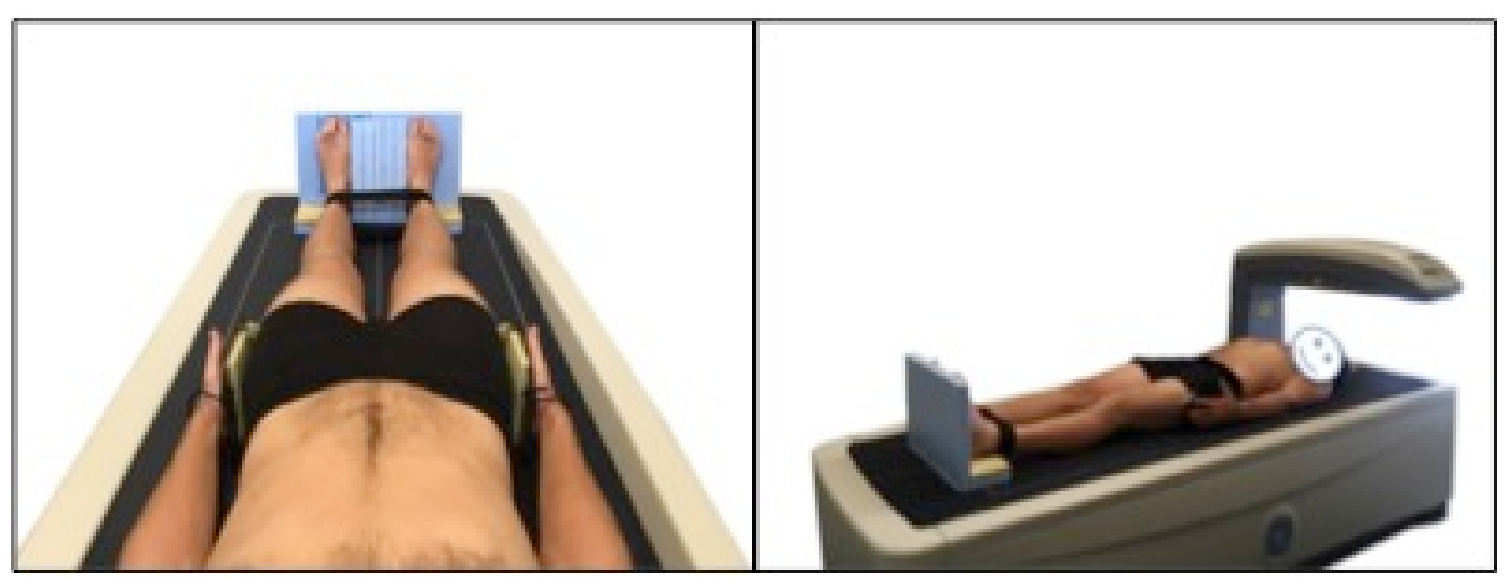

Figure 1. Positioning Protocol. 